\title{
SARS-CoV-2-Infection in Children and Newborn: Less Severe Than in Adults?
}

\author{
Stefan Bittmann*, Elisabeth Luchter, Anne Weissenstein and Gloria Villalon \\ Department of Pediatrics and Ped Mind Institute (PMI), Germany
}

*Corresponding author: Stefan Bittman, Head of the Department of Pediatrics and Ped Mind Institute (PMI), Gronau, Germany.

To Cite This Article: Stefan Bittmann*, Elisabeth Luchter, Anne Weissenstein, Gloria Villalon. SARS-CoV-2-Infection in Children and Newborn: Less Severe Than in Adults?. 2020 - 8(3). AJBSR.MS.ID.001269. DOI: 10.34297/AJBSR.2020.08.001269

Received: March 27, 2020; Published: 眥 April 03, 2020

\section{Introduction}

SARS-CoV-2 Corona virus infection has been reported in December 2019 in Wuhan, China [1-4]. SARS-CoV-2 virus was first described in 2003. Globally, the WHO classified the outbreak as pandemic situation with worldwide rapid spreading in March 2020.

First reports shed light on cases in newborn and children, mostly published by chinese medical doctors and researchers. Few reports described first small series of SARS-CoV-2 infections in pregnant women, who delivered SARS-CoV-2 negative babies $[5,6]$. A number of 190.000 new cases of CoV-2-pneumonia have been reported in adults, including 7807 deaths (date 19/03/2020). In children and neonates, no death was described so far. A possible explanation for this entity could be immature angiotensin II receptors, the primary docking site of spike protein of SARSCoV-19 virus. SARS-Cov-2 infections results in a loss of human life and economy [1,4]. Till the beginning of march 2020, 285 children with SARS-COV-2 pneumonia and 10 newborns were reported to have been diagnosed in China [5,6]. Epidemiological investigations suggest that people are generally susceptible to SARS-COV-2, and some children have a clear family gathering history [2,3]. The national health commission presented in the "corona virus infection pneumonia treatment plan", that children and infants also have the disease (March 2020). The symptoms of some children and neonates are variable, presenting as vomiting and diarrhea and other gastrointestinal symptoms or only showing as weak spirit and shortness of breath. Children with mild symptoms only showed low fever, mild fatigue, and often no pneumonia signs.
To date of March 2020, no clear guidelines of treatment in children due to mild symptoms in newborns and children were classified and ruled out. Severe cases of SARS-CoV-19 described in adults are not described in children and newborn [5]. Moreover, in the few published case reports of SARS-CoV-19 positive pregnant women, after delivery no SARS-CoV-19 positive newborn was described. These early results suggest, that SARS-CoV-19 virus seems not to transfer placental [6]. Further research investigations should include a bigger series of children and newborn with molecular analysis of angiotensin II receptor docking site and their possible immaturity towards docking to spike protein of COVID-19. In this way, losartan could be an option to treat children in severe cases. Further research of this novel viral infection in children is necessary.

\section{References}

1. Zhu N, Zhang D, Wang W, Xingwang Li, Bo Yang, et al. (2020) A novel Corona virus from patients with pneumonia in China, 2019. N Engl J Med 382: 727-733.

2. National health committee of the People's Republic of China. "New coronavirus infection pneumonia diagnosis and treatment plan of 7 (trial version)" $16^{\text {th }}$ of February 2020.

3. Notice on prevention and control of pneumonia epidemic caused by new coronavirus infection in children and pregnant women". 2020, 17:3.

4. Health Kang Wei.

5. Ludwigssons JF (2020) Systematic review of COVID-19 in children shows milder cases and better prognosis than adults. Acta Pediatr.

6. Hong H, Wang Y, Chung HT, Chen CJ (2020) Clinical characteristics of novel coronavirus disease 2019 (COVID-19) in newborns, infants and children. Pediatr Neonatol S1875-9572(20): 30026-30027. 